EXTENDED REPORT

\title{
The relation between birth size and the results of refractive error and biometry measurements in children
}

\author{
S-M Saw, L Tong, K-S Chia, D Koh, Y-S Lee, J Katz, D TH Tan
}

Br J Ophthalmol 2004;88:538-542. doi: 10.1136/bjo.2003.025411

\begin{abstract}
See end of article for authors' affiliations ......................

Correspondence to: Associate professor SeangMei Saw, Department of Community, Occupational and Family Medicine, National University of Singapore, 16 Medical Drive, Singapore 117597 Republic of Singapore; cotsawsm@nus.edu.sg
\end{abstract}

Accepted for publication 1 August 2003

\begin{abstract}
Aim: To examine the association of birth parameters with biometry and refraction in Singapore Chinese schoolchildren.

Methods: Chinese children aged 7-9 years $(n=1413)$ from three schools in Singapore were recruited. Birth parameter information on birth weight, head circumference, length at birth, and gestational age were obtained from standard hospital records. Cycloplegic autorefraction, keratometry and biometry measures (axial length, vitreous chamber depth, lens thickness, and anterior chamber depth) were obtained.

Results: Across the normal birthweight range $(2.0-4.9 \mathrm{~kg})$, children with birth weights $\geqslant 4.0 \mathrm{~kg}$ had longer axial lengths (adjusted mean $23.65 \mathrm{~mm}$ versus $23.16 \mathrm{~mm}$ ), compared with children with birth weights $<2.5 \mathrm{~kg}$, after controlling for age, sex, school, height, parental myopia, and gestational age. For every $1 \mathrm{~cm}$ increment in head circumference at birth, the axial length was longer by $0.05 \mathrm{~mm}$. For every $1 \mathrm{~cm}$ increment in birth length, the axial length was longer by $0.02 \mathrm{~mm}$ in multivariate analysis. Additional week increases in gestational age till 46 weeks resulted in axial lengths that were longer by $0.04 \mathrm{~mm}$, controlling for age, sex, school, parental myopia, and height. Children with larger birth weights, head circumferences, birth lengths, or gestational ages had deeper vitreous chambers and larger corneal curvature radii; however, there were no significant associations with refraction.

Conclusions: Children who were born heavier, had larger head sizes or lengths at birth, or who were born more mature had longer axial lengths, and deeper vitreous chambers; but there were no differences in refraction at ages 7-9 years, possibly because of the observed compensatory flattening of the cornea.
\end{abstract}

T he refractive state of the human eye is dependent on the balance of changes in overall eye size and the refractive components-namely, the cornea and the lens. ${ }^{1}$ Any disturbance in this balance or emmetropisation mechanism results in refractive error. The emmetropisation mechanism is disturbed if degraded visual images reach the retina. In an animal model signals sent to influence scleral remodelling via the choroid led to alteration in eye shape and a longer axial length of the eye. ${ }^{2}$ Intrauterine environmental factors such as infection or maternal disease may influence the fetal and childhood development of ocular structures and alter emmetropisation mechanisms. If there is poor embryological development there may be deficiencies in chemicals involved in retinal signalling mechanisms such as retinoic acid or insulin growth factor leading to alteration of the influence of the retina on eye growth. ${ }^{3}$ The development of myopia most frequently occurs in early childhood and is often accompanied by an increase in axial length. ${ }^{5}$ Eye growth and maturation during the early critical childhood period may be linked to eye development in utero.

Small birth size has been associated with diabetes, coronary heart disease, and poorer cognitive function, ${ }^{6-8}$ while increased birth weight is associated with a higher risk of nuclear cataract in a cohort of 741 adults born in Sheffield. ${ }^{9}$ The evaluation of the relation between fetal growth factors and myopia has been primarily studied in select groups of premature or low birthweight babies. Babies born prematurely, with low birth weight, or with retinopathy of prematurity were found to have higher risks of myopia. ${ }^{10-12}$

To our knowledge, little is known about the effects of the full range of birth parameters (birth weight, head circumference, birth length, and gestational age) on biometry measures and refractive errors in the general population. We aimed to evaluate the influence of birth parameters on the various biometry parameters and refractive error in Singapore Chinese schoolchildren.

\section{PATIENTS AND METHODS}

\section{Study population}

The initial results of the Singapore Cohort Study of the Risk Factors for Myopia (SCORM), of children recruited from three schools in Singapore are shown here. Details of the methodology of the study have been previously reported. ${ }^{13-16}$ In brief, all children aged 7-9 years from three schools in Singapore were invited to participate in the study in November 1999 (Eastern and Northern school) and May 2001 (Western school). Children with serious medical conditions such as congenital heart disease, ocular conditions such as syndrome associated myopia and retinopathy of prematurity, or allergy to eyedrops were excluded. Only Chinese children with ocular data who agreed to participate $(\mathrm{n}=1454)$ were included in the study as we aimed to study an ethnically homogeneous population. There were 41 children with missing birth weight who were also excluded. The participation rate was $64.5 \%$. The proportion of participants who reported short sightedness $(30.8 \%)$ was similar to non-participants $(27.5 \%)(\mathrm{p}=0.27)$. There were 1413 children enrolled: 729 boys and 684 girls. There were 611 children aged 7 years old, 457 children aged 8 years old, and 345 children aged 9 years old. Written informed consent was obtained from the parents after the nature of the study was explained. The study procedures were in accordance with the standards of the ethics committee, Singapore Eye Research Institute, and followed the tenets of the World Medical Association's Declaration of Helsinki.

Birth parameter information

Birth history data were obtained from a documented medical record booklet - the hospital physician or nurse records 
Table 1 Description of birth parameters by sex

\begin{tabular}{lllll}
\hline & Boys & Girls & No & Total \\
\hline Birth weight (kg) & $3.2(0.4)$ & $3.1(0.4)$ & 1413 & $3.2(0.4)$ \\
Mean (SD) (\%) & $3.2(2.0-4.8)$ & $3.1(2.0-4.9)$ & & $3.2(2.0-4.9)$ \\
Median (range) & $38(5.2)$ & $42(6.1)$ & & $80(5.7)$ \\
Low birth weight* (n) & $38.6(1.5)$ & $38.6(1.5)$ & 1248 & $38.6(1.5)$ \\
Gestational age (weeks) & $39.0(32.0-46.0)$ & $39.0(28.0-42.0)$ & & $39.0(34.0-46.0)$ \\
Mean (SD) & $50(7.7)$ & $35(5.9)$ & & $85(6.8)$ \\
Median (range) & $33.9(1.5)$ & $33.5(1.6)$ & 1249 & $33.7(1.6)$ \\
Premature (n) (\%) & $34.0(30.0-45.0)$ & $33.0(30.0-49.0)$ & & $34.0(30.0-49.0)$ \\
Head circumference (cm) & & $48.9(2.3)$ & 1279 & $49.3(2.4)$ \\
Mean (SD) & $49.6(2.4)$ & $49.0(44.0-59.0)$ & & $49.0(44.0-70.0)$ \\
Median (range) & $50.0(44.0-70.0)$ & & \\
Length at birth (cm) & Mean (SD) & &
\end{tabular}

details of the birth history within a few days after birth. Birth parameters documented include birth weight $(\mathrm{kg})$, gestational age (weeks), head circumference $(\mathrm{cm})$, and birth length $(\mathrm{cm})$. Gestational age data for 211 children were also obtained from the National Birth and Death Registry, as there was no gestational age information available for these children from the medical record booklet. This registry captures information recorded on birth certificates by hospital personnel. A validation study of 911 children with gestational age data from both the medical record booklet and the National Birth and Death Registry revealed a Spearman correlation coefficient of 0.92 . Prematurity was defined as gestational age less than 37 weeks and low birth weight defined as birth weight less than $2.5 \mathrm{~kg} .{ }^{17}$ Height was measured standing against a vertical scale (measuring tape) fixed to the wall. The children were instructed to stand without shoes and height was taken with a headpiece held perpendicular to the crown of the head.

\section{Eye measurements}

After instillation of $0.5 \%$ oxybuprocaine (proparacaine) cycloplegia was induced in each eye with three drops of $1 \%$ cyclopentolate instilled 5 minutes apart. At least 30 minutes after the last cycloplegic drop, one of two Canon RK 5 autokeratorefractometers (Canon Inc Ltd, Tochigiken, Japan) was used to obtain the average of five consecutive refraction measurements and the average of the corneal curvature readings in the horizontal and vertical meridia.

One of two calibrated Nidek Echoscan model US-800 biometry units (Nidek Co Ltd, Tokyo, Japan; probe frequency of $10 \mathrm{MHz}$ ) was used to measure axial length, anterior chamber depth, lens thickness, and vitreous chamber depth. The children's eyes were anaesthetised with one drop of $0.5 \%$ oxybuprocaine before the procedure. The average of six axial length measurements was taken and accepted only if the standard deviation (SD) of these six readings was less than $0.12 \mathrm{~mm}$. If not, the measurements were repeated till the best six acceptable axial length measurements were available. The optometrists performing the refraction and biometry measures were masked to birth history information.

\section{Data analysis}

There was a high correlation between right and left eye refraction (Pearson correlation coefficient, $r=0.96$ ). Results from analysing right eye and left eye separately were found to be similar, thus only results of the right eye are presented. The measurements of refraction were analysed as spherical equivalent (SE) (sphere power + half negative cylinder power). Only children with missing birth weight data were excluded from all analyses. There were 164 missing values for head circumference, 134 missing values for birth length, and 165 missing values for gestational age. Children with missing head circumference values were similar with respect to sex $(p=0.21)$, refractive error $(p=0.92)$, axial length $(p=0.42)$, and birth weight $(p=0.91)$, compared with children with head circumference data. Children with missing birth length data had similar distributions of sex $(p=0.07)$, refractive error $(p=0.77)$, axial length $(p=0.15)$, and birth weight $(p=0.91)$, compared with children with birth length data. There was a lower proportion of boys (44.0\%) among children with missing birth length data compared with children who had birth length data $(52.4 \%)$, though the relation did not reach statistical significance. Children without gestational age data were not different by sex $(p=0.40)$, refractive error $(\mathrm{p}=0.37)$, or axial length $(\mathrm{p}=0.41)$ compared with children with gestational age data. Children without gestational age information were heavier at birth (mean $=3.3 \mathrm{~kg}$ ) compared to children with data (mean $=3.2 \mathrm{~kg}$ ), though this relationship did not reach statistical significance $(\mathrm{p}=0.07)$.

The association between the various birth parameters as continuous variables (birth weight, gestational age, birth length, and head circumference) and refraction or biometry parameters were investigated in multivariate linear models, adjusting for age, sex, school, parental myopia, height, and gestational age (except in the analysis of gestational age data). Birth parameters were also analysed according to subcategories defined by standard growth charts. ${ }^{17}$ Linear trend tests were performed by assigning consecutive integers to each group and regressing the dependent variable on this new score. All the associations were also tested on children who were not born prematurely or with low birth weight to check that the associations were not driven by the lowest birth weights or gestational ages. In addition, all data were analysed separately for myopes and non-myopes, as well as by school and sex. All p values are two sided and considered statistically significant when the values are below 0.05. A sample size of 1050 was needed for a two sided hypothesis to detect a mean axial length of $23.6 \mathrm{~mm}$ (SD 1.5) in children with birth weight $\geqslant 4.0 \mathrm{~kg}$ compared with mean axial length of $23.3 \mathrm{~mm}$ (SD 1.5) in children with birth weight $<2.5 \mathrm{~kg}$, if the power $(1-\beta)$ was 0.9 and type I error, $\alpha$, was 0.05 . All statistical procedures used the commercially available software Stata (Version 7.0). ${ }^{18}$

\section{RESULTS}

The mean right eye refractive error (SE) was -0.51 dioptre (D) (SD 1.69), mean cylinder was $-0.50 \mathrm{D}$ (SD 0.67), and mean axial length was $23.39 \mathrm{~mm}$ (SD 0.95). The proportion of children with myopia (SE at least $-0.5 \mathrm{D})$ was $36.9 \%$ (95\% confidence interval (CI); 34.4 to 39.4 ) and $49.4 \%$ (95\% CI; 
Table 2 Ocular biometry and refraction parameters for different birth parameters

\begin{tabular}{|c|c|c|c|c|c|c|c|}
\hline \multirow[b]{2}{*}{ Early life variables } & \multirow[b]{2}{*}{ No } & \multicolumn{2}{|c|}{ Axial length (mm) } & \multicolumn{2}{|c|}{ Vitreous chamber depth (mm) } & \multicolumn{2}{|c|}{ Lens thickness (mm) } \\
\hline & & Mean (SD) & $\begin{array}{l}\text { Adjusted* } \\
\text { mean (SD) }\end{array}$ & Mean (SD) & $\begin{array}{l}\text { Adjusted* } \\
\text { mean (SD) }\end{array}$ & Mean (SD) & $\begin{array}{l}\text { Adjusted* mean } \\
\text { (SD) }\end{array}$ \\
\hline \multicolumn{8}{|l|}{ Birth weight (kg) } \\
\hline$<2.5$ & 80 & $23.17(0.95)$ & $23.16(2.16)$ & $16.13(0.92)$ & $16.09(2.09)$ & $3.49(0.20)$ & $3.50(0.45)$ \\
\hline $2.5-2.9$ & 343 & $23.13(0.85)$ & $23.29(1.26)$ & $16.05(0.80)$ & $16.21(1.21)$ & $3.50(0.17)$ & $3.49(0.26)$ \\
\hline $3.0-3.4$ & 657 & $23.44(0.96)$ & $23.41(0.84)$ & $16.35(0.91)$ & $16.32(0.81)$ & $3.48(0.18)$ & $3.49(0.18)$ \\
\hline $3.5-3.9$ & 288 & $23.67(1.00)$ & $23.53(1.44)$ & $16.56(0.97)$ & $16.44(1.40)$ & $3.46(0.17)$ & $3.48(0.30)$ \\
\hline$\geqslant 4.0$ & 45 & $23.45(0.84)$ & $23.65(2.39)$ & $16.44(0.86)$ & $16.56(2.31)$ & $3.46(0.17)$ & $3.47(0.50)$ \\
\hline $\mathrm{p}$ Value (trend) & & $<0.001$ & $<0.001$ & $<0.001$ & $<0.001$ & 0.009 & 0.25 \\
\hline Regt coefficient & & 0.37 & 0.25 & 0.35 & 0.24 & -0.03 & -0.02 \\
\hline \multicolumn{8}{|c|}{ Head circumference $(\mathrm{cm})$} \\
\hline$<32$ & 67 & $23.17(0.93)$ & $23.22(2.13)$ & $16.09(0.89)$ & $16.13(2.05)$ & $3.48(0.18)$ & $3.51(0.44)$ \\
\hline $32-33.9$ & 508 & $23.24(0.90)$ & $23.33(1.11)$ & $16.16(0.84)$ & 16.25 (1.07) & $3.49(0.18)$ & $3.50(0.23)$ \\
\hline $34-35.9$ & 573 & $23.53(0.97)$ & 23.44 (1.02) & $16.44(0.95)$ & $16.36(0.98)$ & $3.48(0.17)$ & $3.48(0.21)$ \\
\hline $36-37.9$ & 93 & 23.67 (1.02) & 23.55 (1.98) & $16.58(1.00)$ & $16.48(1.91)$ & $3.44(0.17)$ & $3.47(0.41)$ \\
\hline$\geqslant 38$ & 8 & $23.58(0.99)$ & $23.66(3.14)$ & $16.57(0.66)$ & 16.60 (3.03) & $3.44(0.23)$ & $3.46(0.65)$ \\
\hline $\mathrm{p}$ Value (trend) & & $<0.001$ & 0.002 & $<0.001$ & 0.001 & 0.07 & 0.11 \\
\hline Reg coefficient & & 0.09 & 0.05 & 0.09 & 0.05 & -0.005 & -0.005 \\
\hline \multicolumn{6}{|l|}{ Length at birth $(\mathrm{cm})$} & & 0.18 \\
\hline$<47.0$ & 118 & $23.10(0.94)$ & 23.28 (1.95) & $16.06(0.92)$ & $16.22(1.88)$ & $3.49(0.19)$ & $3.49(0.40)$ \\
\hline $47.0-48.9$ & 310 & $23.24(0.95)$ & 23.35 (1.18) & $16.17(0.91)$ & $16.27(1.13)$ & $3.50(0.18)$ & $3.49(0.24)$ \\
\hline $49.0-50.9$ & 531 & $23.44(0.92)$ & $23.41(0.87)$ & $16.35(0.89)$ & $16.33(0.84)$ & $3.48(0.17)$ & $3.49(0.18)$ \\
\hline $51.0-52.9$ & 253 & $23.65(1.01)$ & $23.47(1.40)$ & $16.54(0.96)$ & $16.38(1.35)$ & $3.46(0.17)$ & $3.48(0.29)$ \\
\hline$\geqslant 53$ & 67 & $23.53(0.84)$ & $23.54(2.23)$ & $16.44(0.79)$ & $16.44(2.15)$ & $3.50(0.15)$ & $3.48(0.46)$ \\
\hline $\mathrm{p}$ Value (trend) & & $<0.001$ & 0.022 & $<0.001$ & 0.04 & 0.14 & 0.66 \\
\hline Reg coefficient & & 0.06 & 0.02 & 0.06 & 0.02 & -0.003 & -0.001 \\
\hline $\mathrm{p}$ Value (reg) & & $<0.001$ & 0.044 & $<0.001$ & 0.05 & 0.14 & 0.66 \\
\hline \multicolumn{8}{|c|}{ Gestational age (weeks) } \\
\hline$<37$ & 85 & 23.3110 .92 & $23.29(2.05$ & 16.2110 .89 & $16.21(1.98$ & 3.5210 .19 & $3.50(0.42)$ \\
\hline $37.0-38.9$ & 454 & 23.3310 .96 & 23.35 (1.07 & 16.2510 .92 & 16.2711 .03 & 3.4810 .17 & $3.49(0.22)$ \\
\hline $39.0-40.9$ & 649 & 23.4410 .96 & $23.42(1.00$ & 16.3510 .92 & 16.3410 .97 & 3.4810 .18 & $3.48(0.21)$ \\
\hline $41.0-42.9$ & 58 & 23.4610 .98 & $23.49(1.95$ & 16.3410 .99 & $16.41(1.88$ & $3.47(0.21$ & $3.47(0.58)$ \\
\hline$\geqslant 43$ & 2 & $24.12(1.17$ & 23.56 (3.08 & 17.4410 .94 & $16.48(2.98$ & 3.3310 .18 & $3.46(0.64)$ \\
\hline p Value (trend) & & 0.04 & 0.05 & 0.03 & 0.05 & 0.14 & 0.20 \\
\hline Reg coefficient & & 0.04 & 0.04 & 0.05 & 0.04 & -0.008 & 0.008 \\
\hline p Value (reg) & & 0.014 & 0.028 & 0.01 & 0.017 & 0.016 & 0.027 \\
\hline Early life variables & No & Anterior cham & depth (mm) & Radius of corn & curvature $(\mathrm{mm})$ & Refractive erro & \\
\hline \multicolumn{8}{|l|}{ Birth weight (kg) } \\
\hline$<2.5$ & 80 & $3.55(0.28)$ & $3.57(0.69)$ & $7.65(0.20)$ & $7.66(0.60)$ & $-0.66(1.80)$ & $-0.52(4.15)$ \\
\hline $2.5-2.9$ & 343 & $3.58(0.29)$ & $3.58(0.40)$ & $7.69(0.24)$ & 7.71 (0.35) & $-0.35(1.51)$ & $-0.52(2.41)$ \\
\hline $3.0-3.4$ & 657 & $3.61(0.26)$ & $3.60(0.27)$ & $7.76(0.25)$ & $7.76(0.23)$ & $-0.52(1.74)$ & $-0.52(1.61)$ \\
\hline $3.5-3.9$ & 288 & $3.64(0.27)$ & $3.61(0.46)$ & $7.82(0.23)$ & $7.81(0.40)$ & $-0.67(1.80)$ & $-0.52(2.77)$ \\
\hline$\geqslant 4.0$ & 45 & $3.55(0.26)$ & $3.62(0.76)$ & $7.83(0.25)$ & $7.86(0.66)$ & $-0.24(1.17)$ & $-0.51(4.58)$ \\
\hline p Value (trend) & & 0.008 & 0.26 & $<0.001$ & $<0.001$ & 0.36 & 0.98 \\
\hline Reg coefficient & & 0.05 & 0.04 & 0.11 & 0.10 & -0.08 & 0.02 \\
\hline $\begin{array}{l}p \text { Value (reg) } \\
\text { Head circumference }\end{array}$ & & 0.002 & 0.08 & $<0.001$ & $<0.001$ & 0.41 & 0.84 \\
\hline$<32$ & 67 & $3.60(0.27)$ & $3.58(0.68)$ & $7.65(0.22)$ & $7.69(0.59)$ & $-0.68(1.74)$ & $-0.52(4.04)$ \\
\hline $32-33.9$ & 508 & $3.59(0.29)$ & $3.59(0.36)$ & $7.72(0.24)$ & $7.73(0.31)$ & $-0.40(1.60)$ & $-0.52(2.12)$ \\
\hline $34-35.9$ & 573 & $3.61(0.26)$ & $3.60(0.33)$ & $7.78(0.24)$ & $7.77(0.28)$ & $-0.59(1.74)$ & $-0.52(1.94)$ \\
\hline $36-37.9$ & 93 & $3.65(0.30)$ & $3.60(0.64)$ & $7.82(0.28)$ & $7.81(0.55)$ & $-0.55(1.74)$ & $-0.52(3.76)$ \\
\hline$\geqslant 38$ & 8 & $3.58(0.36)$ & 3.61 (1.01) & $7.89(0.17)$ & $7.86(0.88)$ & $-0.55(1.50)$ & $-0.52(5.98)$ \\
\hline $\mathrm{p}$ Value (trend) & & 0.09 & 0.59 & $<0.001$ & $<0.001$ & 0.39 & 0.98 \\
\hline Reg coefficient & & 0.008 & 0.003 & 0.03 & 0.02 & -0.02 & 0.01 \\
\hline $\begin{array}{l}p \text { Value }(\mathrm{reg}) \\
\text { Length at birth }(\mathrm{cm})\end{array}$ & & 0.11 & 0.56 & $<0.001$ & $<0.001$ & 0.54 & 0.76 \\
\hline$<47.0$ & 118 & $3.56(0.29)$ & $3.57(0.62)$ & $7.66(0.24)$ & $7.69(0.54)$ & $-0.41(1.56)$ & $-0.62(3.71)$ \\
\hline $47.0-48.9$ & 310 & $3.58(0.28)$ & $3.58(0.37)$ & $7.70(0.23)$ & $7.72(0.33)$ & $-0.55(1.73)$ & $-0.57(2.23)$ \\
\hline $49.0-50.9$ & 531 & $3.60(0.27)$ & $3.59(0.28)$ & $7.77(0.24)$ & $7.76(0.24)$ & $-0.49(1.71)$ & $-0.51(1.66)$ \\
\hline $51.0-52.9$ & 253 & $3.65(0.27)$ & $3.61(0.45)$ & $7.81(0.24)$ & $7.80(0.39)$ & $-0.64(1.70)$ & $-0.46(2.66)$ \\
\hline$\geqslant 53$ & 67 & $3.59(0.29)$ & $3.62(0.71)$ & $7.83(0.27)$ & $7.83(0.62)$ & $-0.46(1.53)$ & $-0.41(4.24)$ \\
\hline $\mathrm{p}$ Value (trend) & & 0.004 & 0.24 & $<0.001$ & $<0.001$ & 0.50 & 0.31 \\
\hline Reg coefficient & & 0.007 & 0.002 & 0.02 & 0.01 & -0.008 & 0.02 \\
\hline $\mathrm{p}$ Value (reg) & & 0.03 & 0.53 & $<0.001$ & $<0.001$ & 0.68 & 0.30 \\
\hline Gestational age (we & & & & & & & \\
\hline$<37$ & 85 & $3.57(0.26)$ & $3.58(0.65)$ & $7.74(0.25)$ & $7.72(0.57)$ & $-0.29(1.73)$ & $-0.39(3.90)$ \\
\hline $37.0-38.9$ & 454 & $3.59(0.28)$ & $3.59(0.34)$ & $7.73(0.24)$ & $7.74(0.30)$ & $-0.48(1.70)$ & $-0.47(2.03)$ \\
\hline $39.0-40.9$ & 649 & $3.60(0.26)$ & $3.60(0.32)$ & $7.76(0.24)$ & $7.76(0.28)$ & $-0.58(1.72)$ & $-0.56(1.91)$ \\
\hline $41.0-42.9$ & 58 & $3.65(0.32)$ & $3.61(0.62)$ & $7.80(0.27)$ & $7.78(0.54)$ & $-0.38(1.37)$ & $-0.65(3.70)$ \\
\hline$\geqslant 43$ & 2 & $3.35(0.04)$ & $3.62(0.98)$ & $7.75(0.23)$ & $7.81(0.86)$ & $-2.66(4.83)$ & $-0.72(5.86)$ \\
\hline $\mathrm{p}$ Value (trend) & & 0.30 & 0.41 & 0.03 & 0.03 & 0.16 & 0.21 \\
\hline Reg coefficient & & 0.0069 & 0.005 & 0.01 & 0.01 & -0.045 & -0.039 \\
\hline p Value (reg) & & 0.18 & 0.31 & 0.03 & 0.032 & 0.16 & 0.22 \\
\hline
\end{tabular}


46.8 to 52.0 ) had astigmatism (cylinder at least $-0.5 \mathrm{D}$ ). The proportion of children born with low birth weight was 5.7\%, and $6.8 \%$ were born prematurely (table 1 ). After controlling for refractive error, age, school, height, parental myopia, and gestational age the birth weights of boys were significantly higher compared with girls $(p=0.001)$. The mean head circumference at birth was significantly larger for boys $(33.9 \mathrm{~cm})$ compared with girls $(33.5 \mathrm{~cm})$ and this relation was significant even after controlling for the same factors $(\mathrm{p}<0.001)$. Similarly, length at birth was larger in boys $(49.5 \mathrm{~cm})$ compared with girls $(48.8 \mathrm{~cm})$ in multivariate analysis $(\mathrm{p}<0.001)$. Gestational age was not significantly different for boys and girls, after controlling for other factors. The adjusted mean birth weights were $3.2 \mathrm{~kg}$ for 7 year olds, $3.2 \mathrm{~kg}$ for 8 year olds, and $3.1 \mathrm{~kg}$ for 9 year olds, and these differences were significant after adjusting for sex, school, height, parental myopia, and gestational age $(p=0.001)$. The multivariate adjusted mean birth lengths of 7 year olds were $49.6 \mathrm{~cm}, 49.0 \mathrm{~cm}$ for 8 year olds, and $48.5 \mathrm{~cm}$ for 9 year olds $(\mathrm{p}<0.001)$. Head circumference and gestational age were not significantly different for children of different ages. The Spearman correlation coefficient of birth weight with birth length was 0.71 , birth weight and head circumference was 0.58 , and birth weight with gestational age was 0.38 .

The relations between birth weight, head circumference, birth length, gestational age, and ocular measures (refraction and biometry) are depicted in table 2. The multivariate adjusted mean axial length was $23.65 \mathrm{~mm}$ for children born with birth weight in the highest category $(\geqslant 4.0 \mathrm{~kg})$, and $23.16 \mathrm{~mm}$ for children with birth weight in the lowest category $(<2.5 \mathrm{~kg}$ ) (p for trend $<0.001)$. For every $1 \mathrm{~kg}$ increment in birth weight, the corresponding axial length was longer by $0.25 \mathrm{~mm}$, vitreous chamber deeper by $0.24 \mathrm{~mm}$, and corneal curvature radius longer by $0.10 \mathrm{~mm}$, after controlling for age, sex, school, height, parental myopia and gestational age in three separate multivariate models. There were no significant associations between birth weight and lens thickness, anterior chamber depth, or refractive error in multivariate analysis. The adjusted mean axial length was $23.66 \mathrm{~mm}$ for children born with head circumference $\geqslant 38 \mathrm{~cm}$ and $23.22 \mathrm{~mm}$ for those born with head circumference $<32 \mathrm{~cm}$, after controlling for age, sex, school, height, parental myopia and gestational age. For every $1 \mathrm{~cm}$ increment in head circumference, axial length was $0.05 \mathrm{~mm}$ longer, vitreous chamber deeper by $0.05 \mathrm{~mm}$, the corneal curvature radius longer by $0.02 \mathrm{~mm}$, but there were no significant changes in refraction after controlling for the same factors in three separate multivariate models.

In multivariate analysis, the adjusted mean axial length for children born with birth length $\geqslant 53 \mathrm{~cm}$ was $23.54 \mathrm{~mm}$ and $23.28 \mathrm{~mm}$ in children with birth lengths $<47 \mathrm{~cm}$. Each additional $\mathrm{cm}$ increase in birth length results in an axial length that is longer by $0.02 \mathrm{~mm}$ and vitreous chamber deeper by $0.02 \mathrm{~mm}$, after controlling for age, sex, school, height, parental myopia and gestation, though these relationships were only of borderline significance $(p=0.044$ and 0.05 , respectively). The corneal curvature radius was longer by $0.01 \mathrm{~mm}$. The multivariate adjusted axial length for children born with gestational age $<37$ weeks was $23.29 \mathrm{~mm}$ compared with $23.56 \mathrm{~mm}$ for children born with gestational age of 43 weeks or more, controlling for age, sex, school, parental myopia, and height. Every additional week increase in gestational age till 46 weeks results in an axial length that is $0.04 \mathrm{~mm}$ longer, the vitreous chamber depth $0.04 \mathrm{~mm}$ longer, lens thinner by $0.008 \mathrm{~mm}$, and the corneal curvature radius $0.01 \mathrm{~mm}$ longer in multivariate analyses. In several multivariate models, myopia ( $\mathrm{SE}$ at least $-0.5 \mathrm{D}$ ) was not associated with birth weight (odds ratio $(\mathrm{OR})=0.91 ; 95 \%$ CI 0.66 to 1.25$)$, head circumference (OR $=0.99 ; 95 \%$ CI 0.91 to 1.07$)$, birth length $(\mathrm{OR}=0.95 ; 95 \%$ CI 0.90 to 1.01$)$ or gestational age $(\mathrm{OR}=1.08 ; 95 \%$ CI 0.99 to 1.18$)$. Higher myopia (SE at least $-3.0 \mathrm{D}$ ) was also not associated with any of the birth parameters. Similar relations between the birth parameters with biometry and refraction measures were found in boys and girls.

\section{DISCUSSION}

In our present cohort, children who were born heavier, with larger head sizes, who were longer or more mature at birth had longer axial lengths, deeper vitreous chambers, and flatter corneas, but there were no differences in refractive error. Our study is unique because of the availability of several birth parameters (possible surrogates of fetal growth) including gestational age and comprehensive ocular assessments (cycloplegic refractions and biometry measures) of Singapore children across the normal birthweight range.

In the general population, altered fetal growth may be associated with later changes in tissue composition and development of disease. A study of 1179 American Indians aged 20-39 years revealed that those with lowest and highest birth weights had a higher risk of diabetes mellitus. ${ }^{7}$ Among 3447 women in Helsinki, coronary heart disease was related to low birth weight and short body length at birth. ${ }^{19}$ Larger birth size, a possible surrogate for brain size, was linked to better cognitive ability in a population based cohort study of 3900 adults in the normal birthweight range in the United Kingdom. ${ }^{8}$ The effects of fetal growth on ocular diseases such as cataract have also been evaluated in the general population. In a study of 741 adults in the United Kingdom, there was no association between size of birth and cataract, except for a higher risk of nuclear cataract for adults with increased birth weight. ${ }^{9}$ The authors postulate that maternal hyperglycaemia may lead to defective lens development. In two studies conducted in north Hertfordshire in the United Kingdom, birth weight was not associated with visual acuity in 700 individuals; while results from a sample of 100 men showed alterations in retinal microvasculature in men with low birth weights compared with those with high birth weights. ${ }^{20} 21$ The authors postulate that maternal hyperglycaemia may lead to defective lens development. Several of these studies may be limited by short follow up time, lack of gestational age information, and absence of data on other potential confounding factors. ${ }^{19}$

Our study is unique because of the availability of several birth parameters (possible surrogates of fetal growth) including gestational age and comprehensive ocular assessments (cycloplegic refractions and biometry measures) of Singapore children across the normal birthweight range. There may be variations in fetal or placental growth if there are differences in maternal nutrition, general maternal health, and genes. In turn, the growth of various ocular structures in childhood may be influenced by the production of chemical modulators involved in retinal signalling in utero. To our knowledge, there are no prior studies of the effects of birth size on biometry measures or refraction in the normal population. In our study of children mostly of normal birth weight, children who had higher birth weights, larger heads, who were longer or more mature at birth had longer axial lengths, deeper vitreous chambers, and flatter corneas in dose-response fashions. Importantly, these relations hold across the normal range in the general population and remain significant, even after controlling for childhood growth (measured using height in this study). Myopia in children is primarily axial in nature and our study shows that fetal environmental factors may also influence eye size and shape. Although some eyes with accelerated eye growth in utero may have longer eyeballs in childhood, compensatory emmetropisation such as the flattening of the cornea occurs 
to maintain optical power and the focus of distant images on the retina. ${ }^{22}$ Thus, emmetropic refraction in early childhood is maintained despite alterations in the ocular dimensions of the eye by in utero growth factors. Another interesting point of note is that babies born less mature did not have increased risks of myopia, contrary to the findings of increased risks of myopia in premature babies from previous studies. ${ }^{23-25} \mathrm{~A}$ possible reason for this discrepancy is that there are fewer premature babies in our study population (children recruited from the schools without retinopathy of prematurity) compared with previous reports of clinic patients.

This school based study of birth weights across the normal range has several advantages including the availability of cycloplegic refraction, a long follow up of 7-9 years, adjustment of potential confounders such as near work and parental history, and data on birth parameters (including gestational age) documented by medical personnel. Biometric measures were available to clarify the role of fetal growth factors on axial length, vitreous chamber depth, lens thickness, anterior chamber depth, and corneal curvature. One issue of particular concern is that not all four birth parameters were available for all children in our study. Children without gestational age data had higher birth weights (mean $3.3 \mathrm{~kg}$ ) compared with children who had gestational age data (mean $3.2 \mathrm{~kg}$ ), but this association was only of borderline significance. It is possible that bias may be introduced if children with gestational age data were more likely to have lower birth weights and shorter axial lengths. Children without birth length data were also less likely to be male $(44.0 \%)$ compared to children with birth length data (52.4\%). However, these biases are unlikely as children with and without gestational age and birth length data had comparable biometry and refraction measures. Children with and without missing values for head circumference or gestational age had similar distributions of sex, refractive error, axial length, and birth weight.

The participation rate was fair $(64.5 \%)$, but there was no information on vital birth parameters or biometry measures in non-participants. Our study findings could be explained by selection bias if children with better fetal growth and longer axial lengths were selected into the study, though this is rather unlikely. The presence of childhood myopia is determined at ages 7-9 years and some children who will eventually develop myopia in adulthood may not become myopic by this early age. Another consideration is that this study population recruited from three schools is not entirely representative of the entire country; however, the primary aim of the study is to compare the risk estimates of biometry and refraction parameters for children with different birth measures within this cohort. Future prospective birth cohort studies investigating the role of fetal growth factors on refractive error development in childhood and adult life should be conducted.

In conclusion, across the normal range of birth weights, babies with greater overall body and eye growth were more likely to have longer axial lengths and deeper vitreous chambers in childhood, but refractions remained the same as there was compensatory flattening of the cornea.

\section{ACKNOWLEDGEMENTS}

Financial support: National Medical Research Council (NMRC), NMRC/0695/2002, Singapore.

\section{Authors' affiliations}

S-M Saw, K-S Chia, D Koh, Department of Community, Occupational and Family Medicine, National University of Singapore, 16 Medical Drive, Singapore 117597, Republic of Singapore

S-M Saw, L Tong, D T H Tan, Singapore Eye Research Institute and Singapore National Eye Centre, (SNEC), 11 Third Hospital Avenue, Singapore 168751, Republic of Singapore

Y-S Lee, Department of Pediatrics, National University of Singapore J Katz, Johns Hopkins Bloomberg School of Hygiene and Public Health, Baltimore, MD, USA

S-M Saw, D T H Tan, Department of Ophthalmology, National University of Singapore

\section{REFERENCES}

1 Troilo D. Neonatal eye growth and emmetropisation-a literature review. Eye 1992;5:154-60.

2 Wallman J, McFadden S. Monkey eyes grow into focus. Nature Med 1995; 1:737-9.

3 Mertz JR, Wallman J. Choroidal retinoic acid synthesis: a possible mediator between refractive error and compensatory eye growth. Exp Eye Res 2000;70:519-27.

4 Seko Y, Shimokawa H, Tokoro T. Expression of bFGF and TGF-beta 2 in experimental myopia in chicks. Invest Ophthalmol Vis Sci 1995;36:1183-7.

5 Lin LK, Shih YF, Tsai CB, et al. Epidemiologic study of ocular refraction among schoolchildren in Taiwan in 1995. Optom Vis Sci 1999;76:275-81.

6 Barker DJP, Martyn CN, Osmond C, et al. Abnormal liver growth in utero and death from coronary heart disease. BMJ 1995;310:703-4.

7 McCance DR, Pettitt DJ, Hanson RL, et al. Birth weight and non-insulin dependent diabetes: thrifty phenotype, or surviving small baby genotype? BMJ 1994;308:942-5.

8 Richards M, Hardy R, Kuh D, et al. Birth weight and cognitive function in the British 1946 birth cohort: longitudinal population based study. BMJ 2001;322:199-203.

9 Hall NF, Gale CR, Syddall H, et al. Relation between size at birth and agerelated cataract. Invest Ophthalmol Vis Sci 2001;42:614-19.

10 Holmstrom G, Azazi M, Kugelberg U. Ophthalmological long term follow up of preterm infants: a population base, prospective study of the refraction and its development. Br J Ophthalmol 1998;82:1265-71.

11 Nissenkorn I, Yassur Y, Mashkowski D, et al. Myopia in premature babies with and without retinopathy of prematurity. $\mathrm{Br} J$ Ophthalmol 1983;67:170-3.

12 Quinn GE, Dobson V, Repka MX, et al. Development of myopa in infants with birth weights less than 1251 grams. Ophthalmology 1992;99:329-40.

13 Saw SM, Hong CY, Chia KS, et al. Nearwork and myopia in young children. Lancet $2001 ; 357: 390$.

14 Saw SM, Wu HM, Hong CY, et al. Myopia and night lighting in Singapore children. Br J Ophthalmol 2001;85:527-28.

15 Saw SM, Chua WH, Hong CY, et al. Height and its relationship to refraction and biometry parameters in Singapore Chinese children. Invest Ophthalmol Vis Sci 2002;43:1408-13.

16 Saw SM, Chua WH, Hong CY, et al. Nearwork in early onset myopia. Invest Ophthalmol Vis Sci 2002;43:332-9.

17 Babson SG, Benda Gl. Growth graphs for the clinical assessment of infants of varying gestational age. J Pediatr 1976;89:814-20.

18 StataCorp. Stat Statistical Software: Release 7.0. College Station, TX: Stata Corporation, 2001.

19 Forsen T, Eriksson JG, Tuomilehto J, et al. Growth in utero and during childhood among women who develop coronary heart disease: longitudinal study. BMJ 1999;319:1403-7.

20 Hall N, Sayer AA, Evans J, Rauf A, et al. Visual acuity and its relationship to early growth, eye disease, and aging in North Herffordshire. Ophthalmic Epidemiol 1998;5:83-90.

21 Chapman N, Mohamudally A, Cerutti A, et al. Retinal vascular network architecture in low-birth-weight men. J Hypertens 1997; 15:1449-53.

22 Grosvenor T, Goss DA. Role of the cornea in emmetropia and myopia. Optom Vis Sci 1998;75:132-45.

23 Fledelius HC. Ophthalmic changes from age of 10 to 18 years. A longitudinal study of sequels to low birth weight. I. Refraction. Acta Ophthalmol 1980;58:889-98.

24 Shapiro A, Yanko L, Nawratzki I, et al. Refractive power of premature children at infancy and early childhood. Am J Ophthalmol 1980;90:234-8.

25 Pennefather PM, Clarke MP, Strong NP, et al. Ocular outcome in children born before 32 weeks gestation. Eye 1995;9:26-30. 